Entre lo popular y lo masivo: análisis de las narrativas estéticas de la campaña "No a la Baja" en Uruguay

Anabel Urdaniz

Question, Vol. 1, N. 57, e020, enero-marzo 2018. ISSN 1669-6581

http://perio.unlp.edu.ar/ojs/index.php/question/article/view/4423

FPyCS | Universidad Nacional de La Plata

La Plata | Buenos Aires | Argentina

Recibido: 20-10-2017 Aceptado: 14-11-2017

Cita sugerida: Urdaniz, A. (2018). Entre lo popular y lo masivo: análisis de las narrativas estéticas de la campaña "No a la Baja" en Uruguay. Question, 1(57), e020. doi: https://doi.org/10.24215/16696581e020

\title{
Entre lo popular y lo masivo: análisis de las narrativas estéticas de la campaña "No a la Baja” en Uruguay
}

\author{
Between what is popular and what is massive: analysis of the aesthetic \\ narratives of the No to the Lowering Age campaign in Uruguay
}

\section{Anabel Urdaniz}

Instituto de Investigaciones en Comunicación; Facultad de Periodismo y Comunicación Social; Universidad Nacional de La Plata/ Comisión de Investigaciones Científicas de la Provincia de Buenos Aires (Argentina) anabel_urdaniz@hotmail.com

\section{Resumen}

Durante 2014 Uruguay vivió una intensa maniobra en pos de reformar la Constitución Nacional para bajar la edad de imputabilidad de los jóvenes de los 18 a los 16 años, y equiparar los castigos con el Sistema Penal Adulto. Sectores de la oposición lograron juntar las firmas necesarias para realizar un plebiscito en el marco de las elecciones presidenciales, con el fin de que la sociedad votara por el sí o por el no a la baja. Sin desconocer las cuestiones políticas, económicas y jurídicas detrás del problema, este ensayo profundiza el análisis sobre 
la cuestión estética de la campaña "No a la Baja". Para ello, no sólo se analizaran varios productos comunicacionales de la misma, sino que se propone una mirada retrospectiva en torno a las narrativas estéticas en Latinoamérica, que supieron poner en tensión lo político. Por lo que se indagará en las vanguardias y sus manifiestos artísticos, así como el concepto de obra, autor y arte moderno. Una de las principales reflexiones que atraviesa este ensayo, gira en torno a las narrativas que la campaña supo construir, que en tanto narrativas de entretenimiento, pudieron articular lo popular y lo masivo, desplegando con cuidado estéticoen relación a los modos del gusto y del sentir legitimados- un discurso contra la baja cuya potencial audiencia eran los no convencidos o los que desconocían la temática.

Palabras claves: infancia; narrativas estéticas; arte; América Latina; imputabilidad.

\section{Abstract}

All through the year 2014, Uruguay lived an intense manoeuvre in search of reforming the National Constitution in order to lower the age of imputability (or criminal responsibility of minors), from 18 to 16 years old and, equate the punishments with the adult criminal system. Sectors of the opposition managed to collect enough signatures to organise a plesbicite within the framework of the presidential elections, so people could vote for or against the lowering of imputability age. Without ignoring the political, economic and legal questions behind this problem, this reflexive essay tries to go deep into the analysis of the aesthetic aspect of the "No to the Lowering Age Campaign". For that purpose, the author will not only analise several communicational products, but she also proposes a retrospective view regarding the aesthetic narratives in Latin America, which caused a great deal of tension in politics. Both, avant-gardes and their artistic manifests and the concept of work, author and modern art will be investigated. One of the main reflections that this essay goes through, is over the narratives that such a Campaign could build, which being considered entertainment narratives, managed to articulate what is popular and what is massive, producing with aesthetic care, -attention in relation to legitimated taste and feeling modes- a discourse against the lowering age of imputability, whose potential audience were the non convinced or the ones who ignored the topic.

Keywords: childhood; aesthetic narratives; art; Latin America; age of imputability. 
A principios de 2014 y en pleno año electoral, resurge en Uruguay la discusión en torno a la "inseguridad" que se asocia de manera superficial con los menores y la edad de imputabilidad, en línea con la construcción punitiva de los jóvenes que es legitimada por varios sectores sociales, económicos y políticos. La medida promovida por el candidato presidencial del Partido Colorado, Pedro Bordaberry, proponía la reforma de artículos constitucionales para habilitar la imputabilidad penal para menores de 16 a 18 años. Mediante la junta de firmas, el Partido Colorado apoyado por el herrerismo del Partido Nacional, cuyo candidato era Luis Lacalle, lograron llamar a un plebiscito para que sea la sociedad quién decida si punir a los jóvenes a partir de los 16 o no. Vale la pena destacar que el plebiscito se realizó junto con las elecciones presidenciales y parlamentarias de ese año, lo que puso el tema en agenda hasta la elección, e incluso definió plataformas electorales. Asimismo, el partido oficialista de ese momento, el Frente Amplio, liderado por José "Pepe" Mujica, se mostró en total oposición a la medida y públicamente en acuerdo con la campaña "No a la Baja".

Las organizaciones sociales e instituciones nucleadas en defensa de los derechos de los niños y las niñas comenzaron a tomar protagonismo y a instalar en los medios tradicionales y digitales, sus argumentos en contra de la baja en la edad de imputabilidad. Al final del proceso, el resultado del plebiscito que al principio parecía a favor de la baja, dio un batacazo y finalmente ganó el NO por un 53.19\% -para lograr la reforma constitucional se necesitaba el $50 \%$ más uno de los votos-. Si bien el hecho necesita de una profunda investigación que contextualice históricamente la niñez uruguaya, la política y las medidas económicas respecto a esa franja etaria, es posible señalar algunas premisas o huellas en la presentación estética de la campaña, como uno de los motivos por el cual pudo ganarse esta consulta popular.

\section{Breve panorama de la baja en la edad de imputabilidad en Latinoamérica}

La escalada de violencia es un hecho en todo el continente, sin embargo la vinculación de esa violencia con los y las adolescentes y jóvenes carece de estadísticas que lo sustenten. Sino que responde a las construcciones sociales de sentido de los medios de comunicación monopólicos, los partidos políticos y el poder judicial. La demagogia punitiva criminaliza la pobreza y la juventud, generando equivalencias discursivas como "pobre y joven", igual a "menor", igual a "delincuente" (1).

Si bien, la edad mínima de punir a las y los adolescentes con castigos que conlleven la privación de la libertad, no está inscripta en la Convención Internacional sobre los derechos de la Niñez, las Reglas de Beijing recomiendan que no sea fijada a una edad demasiado temprana. Por su parte, la Comisión Interamericana de Derechos Humanos recomienda "el establecimiento de la edad mínima de responsabilidad penal lo más cerca posible de los 18”, y 
reafirma que "el principio de la no regresión del derecho penal excluye la posibilidad de bajar la edad".

Sin embargo en América Latina y El Caribe la situación es grave, ya que existen países como Trinidad y Tobago donde la edad mínima es de 7 años. El promedio según estadísticas de UNICEF (2016) es de 12,4 años, lo que indica que la mayoría de los países no está en línea con los tratados. En los últimos veinte años se han intentado reformas para bajar la edad de responsabilidad penal en Argentina (16 años); Ecuador y Brasil (18 años); Colombia (14 años); Panamá (14 años); Perú (14 años) y Costa Rica (14), entre otros.

Lo paradójico es que las propuestas surgen en años electorales y se centran sólo en lo punitivo, omitiendo el debate en torno a las condiciones de vulnerabilidad donde son privados de su libertad los y las jóvenes, en relación a los adultos que sostienen los aparatos criminales o en la plena aplicación de legislación en torno a la promoción y protección de los derechos de la niñez, la adolescencia y la juventud (2).

Este artículo considera necesario analizar la producción comunicacional en torno a la campaña "No a la Baja", ya que en la Argentina en varias oportunidades existieron ofensivas de este tipo (2009-2013-2015), con el agravante que, por primera vez en enero de 2017, el Ministro de Justicia y Derechos Humanos, German Garavano confirmó la intención del Ejecutivo Nacional de bajar la edad. Lo que ocasionó un revuelo espontáneo en el que las redes digitales fueron medios/mediaciones protagonistas. De allí en adelante se organizaron dos movimientos: \#ArgentinaNoBaja y \#NoalaBajaenArgentina, ambos se inspiraron en la campaña uruguaya para proponer aportes respecto a la discusión del tema. Solo como ejemplos, el primer movimiento emplea el colibrí -símbolo uruguayo que se hizo famoso- y el espacio \#NoalaBaja en Argentina organizó una charla que tuvo como protagonistas a los integrantes de la campaña uruguaya.

\section{Materiales a analizar}

Para el análisis se tuvieron en cuenta los siguientes materiales audiovisuales de la campaña "No a la Baja" en Uruguay: el spot "Tango No Baja" y el spot "Nada crece a las sombras". Ambos forman parte de la página web de la campaña (3). Además, se tomarán las principales imágenes, para poder desnaturalizar las ideas claves y observar cómo construyeron a través de propuestas comunicacionales con alto cuidado estético otra mirada en torno a lo que es ser niño, niña, adolescente o joven en Uruguay. Asimismo, se tomará como corpus de análisis una producción audiovisual del Colectivo Catalejo (4), el documental Dieciséis y una campaña en Facebook llamada "Crecer con oportunidades" en vínculo con el largometraje. 
La problematización del objeto conlleva, en primera instancia, conceptualizar e historizar el sentido de arte y estética. Algunas de las preguntas que pretende indagar el artículo giran en torno al sentido de obra presente en las producciones de la campaña "No a la Baja", los recursos empleados, la neutralización del lenguaje y cómo se entrelaza lo masivo y lo popular en los respectivos productos. La elección de este material de análisis permite re-pensar mediante el análisis estético, el rol de las estrategias comunicacionales en torno a una problemática económica y social planteada desde un hecho político.

\section{Modernidades y vanguardias Latinoamericanas}

"La modernidad es lo transitorio, lo fugitivo, la contingencia, la mitad del arte, cuya otra mitad es lo eterno y lo inmutable". Baudelaire, 1863

En primer lugar se considera necesario establecer algunos parámetros claves para entender la modernidad como procesos "heterogéneos y multitemporales" (García Canclini, 2013) en nuestra América Latina. Desde esas nociones será posible dimensionar el rol de las vanguardias y por lo tanto la funcionalidad de los manifiestos estéticos y políticos, lo que implica repensar la categoría de obra de arte. Edgardo Vigo nos lleva a "revulsionar" el campo y pensar nuevas formas de concebir la producción artística en tanto señalamientos. Se inaugura en este punto la imprescindible e impaciente necesidad de re-pensar el espacio público moderno, irrumpido por estas visiones del arte en la calle.

Escribir en torno a la modernidad nos propone la discusión multitemporal de la realidad. Conlleva re-pensar los procesos de enculturación, la formación de las divisiones políticas, la irrupción de los medios masivos de comunicación y la distinción analítica entre lo popular, lo culto y lo masivo. Pero aún más importante, la delimitación de lo moderno nos conduce irremediablemente a pensar el futuro. A conceptualizar los cambios que han provocado la irrupción de soportes y plataformas que permiten la digitalización, el almacenamiento de grandes datos y la convergencia de soportes y lenguajes, entre otros procesos.

En Todo lo sólido se desvanece en el aire, Berman Marshall (2014) divide el proceso de la modernidad en tres grandes fases: la primera desde comienzos del siglo XVI hasta finales del siglo XVIII, que caracteriza como "el tropiezo con la modernidad".

"Las personas buscan desesperadamente, pero medio a ciegas, un vocabulario adecuado; tienen poca o nula sensación de pertenecer a un público o comunidad moderna, en el seno de la cual pudieran compartir sus esfuerzos y esperanzas" (Berman, 2014: 15). 
La segunda etapa la caracteriza como la fase revolucionaria, desde 1790 hasta finales del siglo XIX. En este momento se descubre el espacio público en tanto espacio colectivo de nominar los nuevos procesos. "Sensación de vivir en dos mundos", dirá Berman. En esta fase es donde el autor observa que las cuestiones materiales, los procesos económicos, empiezan a discernirse de las experiencias y las formas de sentir-ser moderno. Por ello realiza la distinción entre procesos de modernización para delimitar los cambios económicos o materiales, mientras que entiende a la modernidad como las nuevas formas de vivir. Por último, la tercera fase se extiende del siglo XX a la actualidad e implica la globalización del proceso de modernización, el avance de las tecnologías electrónicas y digitales y la cultura del modernismo.

Esta distinción entre modernidad y modernización también la retoma Néstor García Canclini cuando hace referencia a la "heterogeneidad multitemporal" (2013) de la cultura moderna latinoamericana. Las hibridaciones culturales le posibilitan al autor conocer los procesos de enculturación sin desconocer la dominación, pero sin reducirlos a mera imposición, al reconocer los diferentes entrelazamientos de lo culto, lo popular y lo masivo.

En términos del autor, las distintas disciplinas han intentado generar objetos puros de lo culto, lo popular y lo masivo,

\begin{abstract}
la historia del arte y la literatura (...) había identificado repertorios de contenidos que debíamos manejar para ser cultos (...) La antropología y los populismos políticos, al reivindicar el saber y las prácticas tradicionales, constituyeron el universo de lo popular. Los comunicólogos y sociólogos atendieron el tercer sistema que engendraron las industrias culturales: sistema de mensajes masivos (García Canclini, 2013: 38).
\end{abstract}

Esta necesidad de conservar lo puro y conformar universos autosuficientes, hizo perder de vista la transformación que sufrían cada uno de esos espacios, mediante una mirada compleja que permita observar la relación de poderes. En la misma línea, Martín-Barbero entiende que si bien la construcción de las masas en masa, permitió darles a las clases populares visibilidad política y un lugar en la esfera pública, este movimiento de entrada a las arenas donde se legitimaba la cultura burguesa, no implicó la revolución social sino una recomposición de la hegemonía "desde adentro", mediante "dispositivos de consenso" (Martín-Barbero, 2003: 164).

\footnotetext{
Masa, designa (...) el modo como las clases populares viven las condiciones de existencia (...). Pues es, en ese momento, en que la cultura popular tendía a convertirse en cultura de clase, será esa misma cultura la minada desde dentro y transformada en cultura de masa (Martín-Barbero, 2003: 165)
}

Es en el siglo XIX, en el que la cultura se convierte en espacio estratégico de mediación para construir hegemonía, mediante la reconciliación de gustos y borronamiento de las diferencias. 
Los medios de comunicación y las industrias culturales en general, tuvieron un papel protagónico en darle legitimidad a esa cultura que cubre el conflicto en un imaginario que integra al mercado, las demandas de las masas.

La pregunta por la comunicación de los procesos históricos a través de las estéticas es una que nos puede acercar a aprehender de qué hablamos cuando decimos hibridaciones. $Y$ en este punto es preponderante destacar el rol que han ocupado las vanguardias artísticas en promover la utopía y la idea de "futuro". El crítico paraguayo Ticio Escobar (1998) se pregunta en uno de sus textos: “¿Cómo adecuar la circularidad sincrónica del lenguaje con un proyecto transido de temporalidad, lanzado hacia el rumbo claro que señala la utopía?”, y afirma que son las vanguardias las "cartas fundamentales" para superar esas contradicciones, mediante acciones que fuercen el lenguaje hasta el límite, "hasta obligarlo a soltar otros nombres de la realidad desde los cuales transformarla" (Escobar, 1998: 11).

Uno de los ejemplos más importantes en Latinoamérica, es la producción muralista que en México protagonizaron artistas como Ángel Orozco, Diego Rivera y Alfaro Siqueiros. En esos murales es posible ver representados a los grandes latifundistas miembros de la oligarquía, pequeñas comunidades campesinas, la bandera española, infraestructura francesa y las imágenes de calaveras, tradición ancestral del día de muertos. La mixtura nos impide pensar en una modernidad tardía -respecto a Europa- y homogénea, sino en procesos complejos, diferentes y, ante todo, heterogéneos. Aún hoy los procesos híbridos son las mayores riquezas, que por coerción, cohesión y consenso, construyen el palimpsesto cultural de nuestra América Latina.

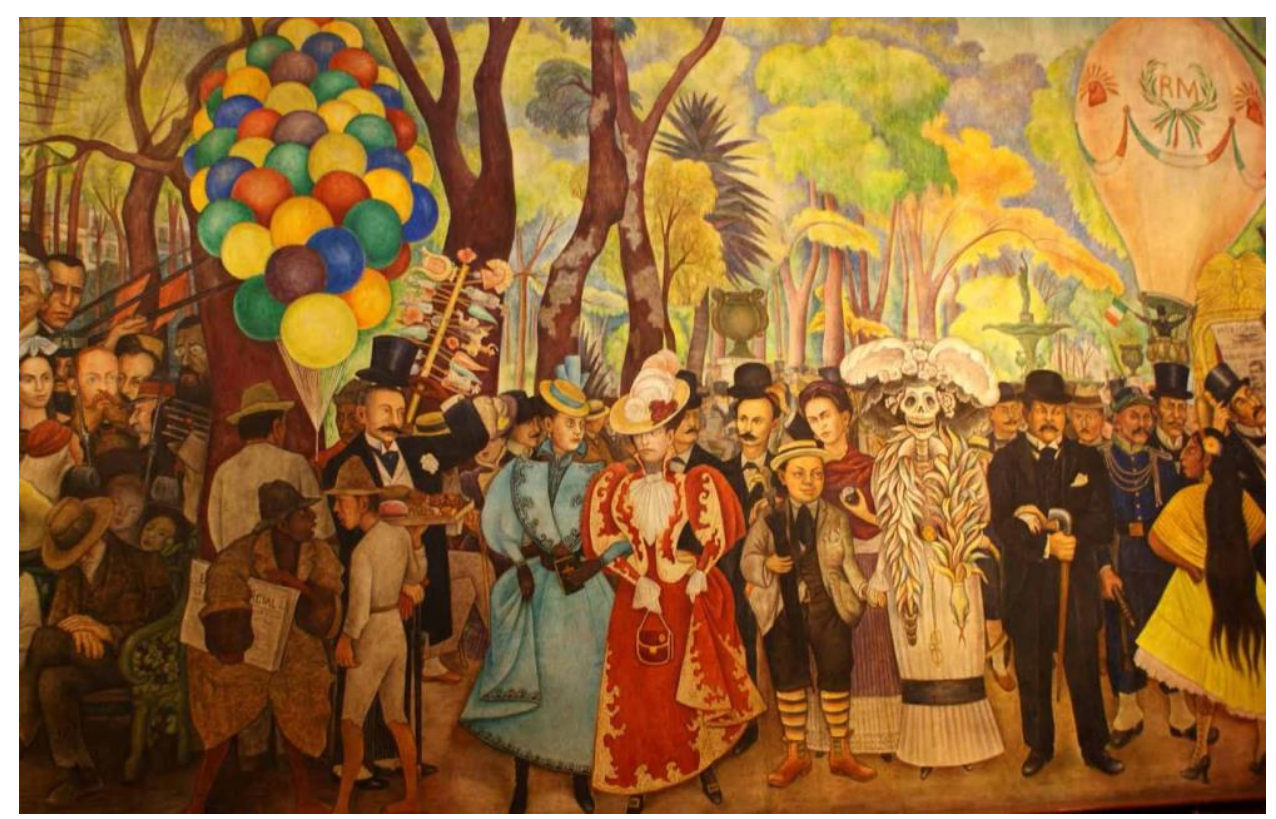

Figura 1: "Sueño de una tarde dominical en la alameda", mural de Diego Rivera realizado en 1947. 


\section{Rol de las vanguardias en la tercera fase de la Modernidad}

Las vanguardias argentinas y latinoamericanas se presentan críticas hacia las instituciones formales que delimitan el campo artístico e intentan refundar las concepciones de obra, autor y arte moderno. Esto implicó poner en jaque las instituciones de su propia formación. Se observa en estos movimientos una búsqueda del "arte nuevo", del "hombre nuevo", de los "nuevos caminos" y de las "nuevas formas" que terminan, en muchos casos, recuperando los antiguos tradicionalismos. Las vanguardias implican la recuperación de lo popular en pos de desestabilizar y cuestionar lo culto.

Estos movimientos "paradigmáticos de la modernidad" (García Canclini) destruyen el concepto de obra orgánica y vuelven las piezas fragmentadas, lo que permite diversos tipos de lecturas. Además, se caracterizarán por emplear mecanismos de imprevisibilidad y shock y, sobre todo, intervenciones que fomenten la participación activa de los espectadores. Las vanguardias artísticas latinoamericanas de la década del veinte no sólo ponen en tensión el statu quo del arte sino que intentan reorganizar el estatuto de autor, obra y receptor. En este sentido señala Mariela Alonso:

\footnotetext{
El autor puede no ser un excelente técnico artesano, sino poseer una conceptualización teórica del hacer. Puede ser tanto hacedor como ideador, puede en lugar de hacer, tomar como el fotógrafo o el camarógrafo-. El artista dadá toma algo y lo produce, cortando, pegando, transmutando, poniéndolo en otro lugar (Alonso, 2016: 46).
}

Resulta significativa esta forma de ver la obra como juego en el espacio, capaz de ser tomado, transmutado, colonizado y violentamente resignificado, en relación a los usos y las apropiaciones que realizan los movimientos sociales de las plataformas digitales. Lugar del "azar, utópico, fragmentario" como lugar de lucha, lugar público por lo tanto factible de ser político, lugar de incidencia y por tanto lugar de transformación.

La aparición de las vanguardias artísticas configuró la distinción entre el arte por el arte mismo y el arte comprometido políticamente. Es posible observar, por ejemplo, el cambio que sufrieron las obras de Antonio Berni al llegar desde Europa y ver las problemáticas de Argentina y de Latinoamérica. Sus obras "Desocupados", "Chacareros" y "Revolución" son una muestra no sólo de las nuevas técnicas sino de su compromiso social, lo que está en relación con la visita del muralista David Alfaro Siqueiros al museo de Bellas Artes, donde afirmaba: "El salón muestra el vacío infinito que aparece cuando falta la convicción social en la obra plástica. Para la inmensa mayoría de los expositores nada parece significar la existencia de 50 millones de desocupados hambrientos en el mundo entero" (Alfaro Siqueiros, 1933). 
Esta concepción de lo estético comprometido social y políticamente va a generar tajantes divisiones entre artistas como Berni, que realizará obras que participen del debate político, económico y social, y otros que quedan al margen. En la década del treinta el poeta y crítico de arte, Cayetano Cordova Iturburu dirá: "El que no pone su inteligencia, su arte, lo mejor que tiene, al servicio de la revolución, lo pone por ese hecho al servicio de la burguesía o lo que es lo mismo al servicio de la injusticia social. Mientras medio mundo se lanza sobre otro medio mundo, la imparcialidad no es posible ni justificable". Esta cita pertenece a uno de los libros de Cordova Iturburu donde debate con Borges, quien ante la pregunta "¿Debe estar el arte al servicio del problema social?", evade contestar.

En su libro Las vanguardias Itinoamericanas, Jorge Schwartz (2002) se pregunta por los lectores de esas producciones:

¿Quiénes leían la vanguardia estética? ¿Quiénes leían la vanguardia política? En ambos casos parece que se trataba de una minoría letrada que, aunque no fuese significativa numéricamente, conformaba una elite capaz de operar cambios, tanto en el campo intelectual como en el campo político (2002: 42).

Esta pregunta nos lleva a pensar en los accesos y en la real incidencia de estas producciones artísticas en el campo de lo popular. A los comienzos del siglo $X X$ ya es posible concebir una incipiente industria cultural en Latinoamérica, ¿Cuánto de las obras vanguardistas de la época era consumida por las clases populares? La pregunta se orienta a pensar de qué forma esa obra podía representar a los cincuenta millones de hambrientos en el mundo y a sus condiciones de vulnerabilidad y problemáticas sociales localistas, y en si esas personas podían leer en esas obras una forma de ser narrados, una forma de encontrarse en el lenguaje estético.

Si algo es seguro del planteo de Judit Butler en Lenguaje, poder e identidad es que el lenguaje que nombra permite ser.

Aquel que actúa (que no es lo mismo que el sujeto soberano) actúa en la medida en que él o ella es constituido en tanto que actor, y por lo tanto, opera desde el principio dentro de un campo lingüístico de restricciones que son al mismo tiempo posibilidades (Butler, 2004: 21).

En términos de lo que Judith Butler llama "supervivencia lingüística", las obras de las y los artistas comprometidos dieron lugar a la puesta en escena de las problemáticas, sin embargo la violencia de la representación y la vulnerabilidad lingüística recaen sobre los sujetos de derechos en tanto objetos narrados. En el ámbito de los derechos de la niñez, la adolescencia y la juventud, éste es un problema característico. Mientras que los sujetos vulnerados son los niños y las niñas, los adultos extraña vez generan espacios donde se garantice la circulación 
no estructurada de la palabra. Incluso, podríamos señalar la ausencia de programas, concursos o convocatorias de los gobiernos que impliquen que ellos y ellas mismas narren estéticamente sus realidades.

La construcción del lenguaje del poder sobre nuestros niños y niñas implica una vulnerabilidad lingüística que se reproduce en prácticas concretas: cacheos de la policía por el color de piel, aprietes de narcos por la condición de pobre, violación y entrada al circuito de tratas de las adolescentes... muertes. Sin embargo es ese reconocimiento violento del otro, el que, en muchas oportunidades, permite poner en escena al sujeto.

Las vanguardias reconocían a un otro marginal y una de sus herramientas de lucha constitutiva era el manifiesto, instrumento y actor que merece una mención.

\section{Manifiestos de las vanguardias latinoamericanas}

"Vamos a sacar la producción pictórica y escultórica de los museos -cementerios- y de las manos privadas para hacer de ellas un elemento de máximo servicio público y un bien colectivo, útil para la cultura de las grandes masas populares". Manifiesto Muralista, Siqueiros,

1923.

"Contra todos los importadores de conciencia enlatada. La existencia palpable de la vida.(...)Queremos la revolución Caraiba. Sin nosotros Europa no tendría si quiera su pobre declaración de los derechos del hombre". Manifiesto Antropofágico, Oscar De Andrade, 1928.

"Es así como, al dar la espalda a las necesidades y luchas del hombre latinoamericano, vacía de contenido su obra, castrándola de toda significación, pues ya no tiene nada trascendente que decir. Se limita entonces a un mero juego con los elementos plásticos (...) pero de ninguna manera es arte, ya que éste sólo es posible cuando se produce una total identificación del artista con la realidad de su medio". Manifiesto del Grupo Espartaco, Argentina, 1959.

Se podría caracterizar al manifiesto artístico como una provocación y una "una suerte de declaración de principios artísticos, políticos y literarios que adquiere con el correr del tiempo el carácter de discurso" (Geymonat, 2011: 4). El manifiesto evoca lo diferente, lo que muchas veces no se nombra, no es representado; es ante todo instituyente, va en contra de lo hegemónico y busca legitimación y abrir espacios de disputas en el marco de la construcción de las tramas simbólicas que él mismo crea. En esas imbricaciones entre el espacio físico real y los enunciados discursivos, simbólicos e imaginarios, es que actúan. Si lo analizáramos en 
término de la lógica de los campos de Pierre Bourdieu, podríamos conjeturar que se trata del reconocimiento a través del lenguaje del capital simbólico presente en las producciones artísticas, que buscan disputar poder político.

Existen una serie de características fundamentales que se repiten en la mayoría de los manifiestos latinoamericanos: la necesidad de ocupar el espacio público y llegar a las "grandes masas populares", lo que implica pensar la obra desacralizada pero también por fuera del circuito del mercado de las incipientes industrias culturales; En la misma línea, se encuentra presente en los manifiestos, la construcción de Europa como otredad de la que las corrientes estéticas se diferencian políticamente. Aquí, se conjugan la necesidad de descolonizar el arte y la de construir una identidad nueva. Por último, en todos los casos se evidencia la necesidad de pensar el arte en relación con la realidad, como representación que exprese las luchas sociales y las desigualdades de Latinoamérica.

Las formas lúdicas y sagaces de escribir las realidades ha sido característica de estos discursos que, en tanto enunciados activos socialmente, fueron instituyendo formas de hacer. En este punto, es preponderante destacar la idea de narrativas que se fueron estableciendo a partir de estas corrientes artísticas, en tanto dispositivos de poder para contar realidades.

\section{Campaña "No a la Baja": aspectos relevantes}

Si bien en varios apartados del artículo se dejaron entrever algunas preguntas y premisas respecto al objeto a estudiar, en este punto se describirá el corpus de análisis para poder conjugarlo respecto a algunas de las categorías anteriormente explicitadas.

La campaña uruguaya "No a la Baja" tenía como lugar articulador de todos los materiales artísticos una página web. El ícono característico de la campaña era un colibrí hecho de papel de varios colores con la consigna "No a la Baja". Dentro de las propuestas audiovisuales se tomaron el spot "Nada crece a las sombras", que aglutina imágenes de la grabación del tema característico de la campaña, con la participación de artistas conocidos como la banda "Contra las Cuerdas", Santi Mostaffa, Gonzalo Brown, Mateo Moreno, Pedro Alemany, Maia Castro, Pata Kramer, Ana Prada, Jorge Schellemberg y Bruno Cammá; e imágenes del mega recital de música que realizaron en el Velódromo (Montevideo) protagonizado con bandas como Ruperto Rocanrol, Alberto Wolf y Los Terapeutas, La Triple Nelson y la murga Agarrate Catalina.

El spot "Tango No Baja" está realizado en una tradicional tanguería con los pisos azulejados negros y blancos y a medida que avanza el corto, se observa la presencia de colibrís de papel colgados en los techos. Una de las profesoras de la tanguería toma la palabra y hace referencia a lo peligroso de "excluir a alguien de la pista". También interviene en el spot un bandoneonista, que por momentos se ve tocando en vivo. 
Por último, se eligió como parte del objeto empírico un largometraje del Colectivo Catalejo titulado "Dieciséis", en el que 16 jóvenes de diferentes edades (entre los 15-18) toman la palabra y contestan preguntas en torno a sus vidas, contextos, experiencias y recorridos.

\section{Narrativas del entretenimiento para defender derechos}

Entre algunas de las características más relevantes de la campaña se encuentra la ocupación de las calles y el espacio público en general, la construcción de frases emocionales y neutralizadas políticamente, la calidad audiovisual y la instantaneidad en los recursos transmedia, lo que conllevó una fuerte construcción identitaria.

La conjunción de varias de estas premisas nos permite pensar cómo la campaña fue convirtiéndose en una narrativa del entretenimiento, cómo fue articulando las frases cortas no combativas sino informativas, explicativas, con videos que articulan el reggaetón y la canción pop con alta calidad de planos y buenas tomas fotográficas. Hay un cuidado de la estética en relación a la calidad de la imagen, los planos y el guión argumentativo, que a simple vista no nos permite relacionarla con organismos que luchan por los derechos, teniendo en cuenta los pocos recursos con los que normalmente cuentan.

Cuando se menciona el "cuidado estético" se da cuenta de producciones audiovisuales que reconocen las construcciones de sentido del "gusto medio, el más común de todos los gustos" (Rincón, 2006: 17) y el sentimiento estético de época: "su condición de deseo, el derecho a la belleza y de aspiración de las masas" (Rincón, 2006: 14).

La campaña "No a la Baja" es una vanguardia política pero sus manifiestos estéticos se ofrecen desde una narrativa mediática. En este sentido se emplea el concepto de Omar Rincón respecto a las "narrativas mediáticas" como las producciones de los medios masivos de comunicación, en tanto construcciones de sentido que habilitan nuevos tiempos, territorios y subjetividades estructuradas por la lógica del entretenimiento.

Las culturas mediáticas son y responden a lo más común, a lo que más junta, a lo que más se identifica con la clase media; es pura «medianía» entre todo; «medianía » entre artes y modas, entre filosofías y estilos, entre discursos y formatos, entre sujetos y masas, entre razones y sentimentalidades (Rincón, 2006: 21)

El trabajo plantea el desplazamiento de entender aquellas narrativas empleadas no ya desde los medios, sino como posicionamiento estético de estas organizaciones, en tanto están dispuestas en la lucha por la hegemonía desde adentro. No generan un nuevo espacio de disputa, quieren luchar ese espacio con las herramientas que ofrece la cultura mediática. "Es 
necesario comenzar a utilizar otros modos intrínsecos de los medios para imaginar narraciones de más utilidad social y política" (Rincón, 2006: 11).

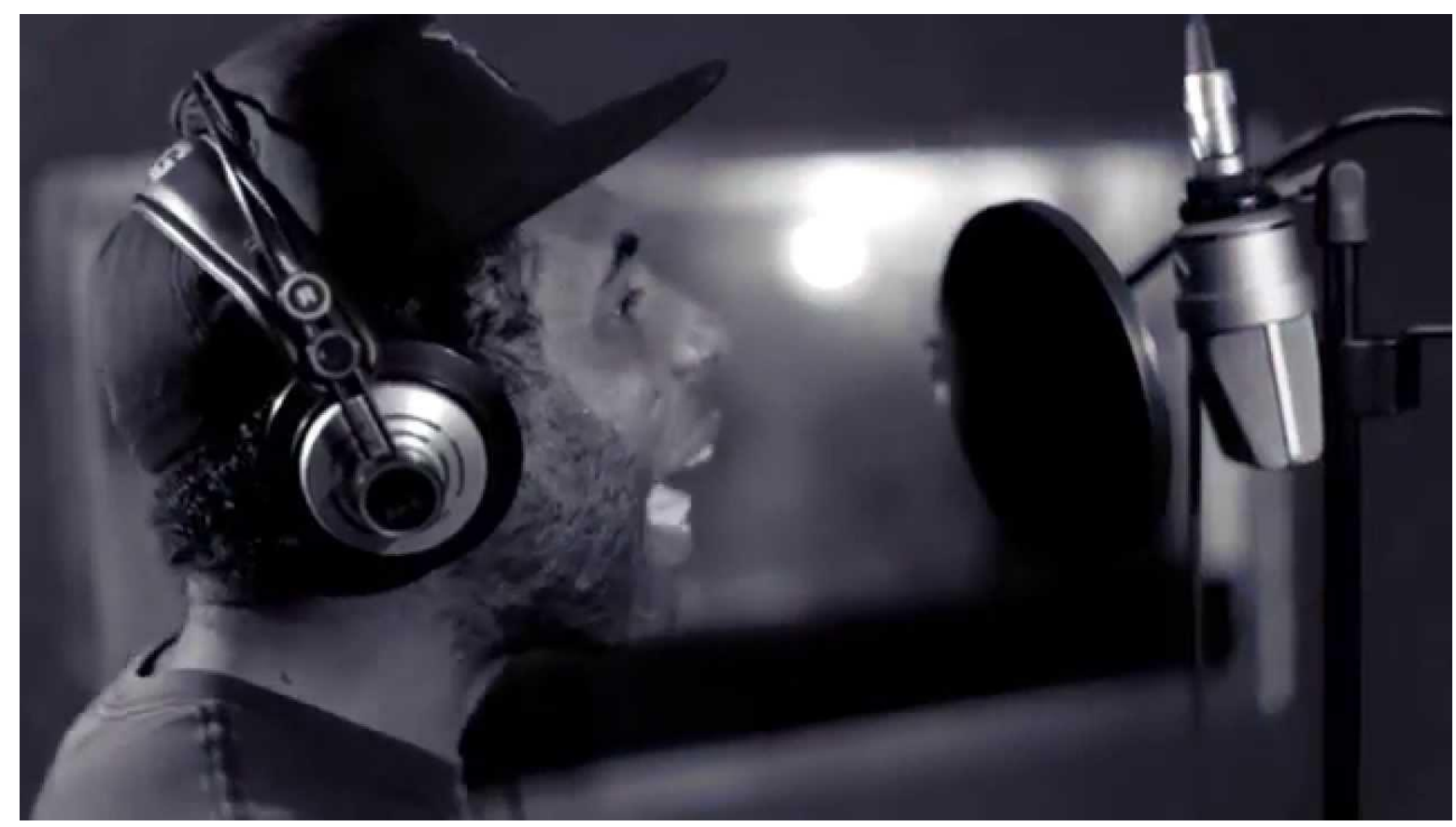

Figura 2: Fotografía de Gonzalo Brown durante la grabación del tema Nada crece a las sombras.

La lógica del entretenimiento entendida como deseo, como seducción y encantamiento vive y se reproduce en las narrativas mediáticas, que nos cuentan el mundo. Sus principales características están relacionadas con el facilismo, lo predecible, lo efectista, el exceso, el show, la velocidad, la repetición, las fórmulas y las emociones instantáneas (Rincón, 2006). De nada sirve criticar desde el racionalismo estas fórmulas, si son desde las que hablamos.

En el spot Nada crece a las sombras se puede ver en calidad HD un concierto al estilo hollywoodense donde las personas en su mayoría "bien arregladas" y de manera ordenada, levantan las manos y corean una de las canciones que fue clave en todos los materiales de la campaña.

La melodía suena suavemente como una especie de canción-rap. Profesionales del canto, la mayoría de ellas y ellos eran famosos que bailaban mientras cantaban:"Dale una oportunidad real y veras, que esa es la manera, si es otra la escuela oh.. oh, son otras las secuelas/Dale una oportunidad real y verás, porque las horas pasan/pensá haciendo una pausa, decile no a la baja"(5). No hay palabras del campo popular, se emplea un lenguaje neutralizante, útil para controlar la sensibilidad política, la música es al estilo hit y con acordes simples que resuenan al instante y son fáciles de corear. Si bien en una parte del rap se menciona la famosa frase que ha sabido ser eslogan de estas campañas "ningún pibe nace chorro", la misma no es el cuerpo del tema, sino que en la mayor parte de la canción hay una construcción de un otro que 
debe decidir, "que tiene que pensar", "que tiene que darle una oportunidad" a los y las jóvenes. No se crean nuevos significados sino, tal como dice Escobar, se intenta "movilizar los significados estancados y sacudir los imaginarios entumecidos" (1998: 13).

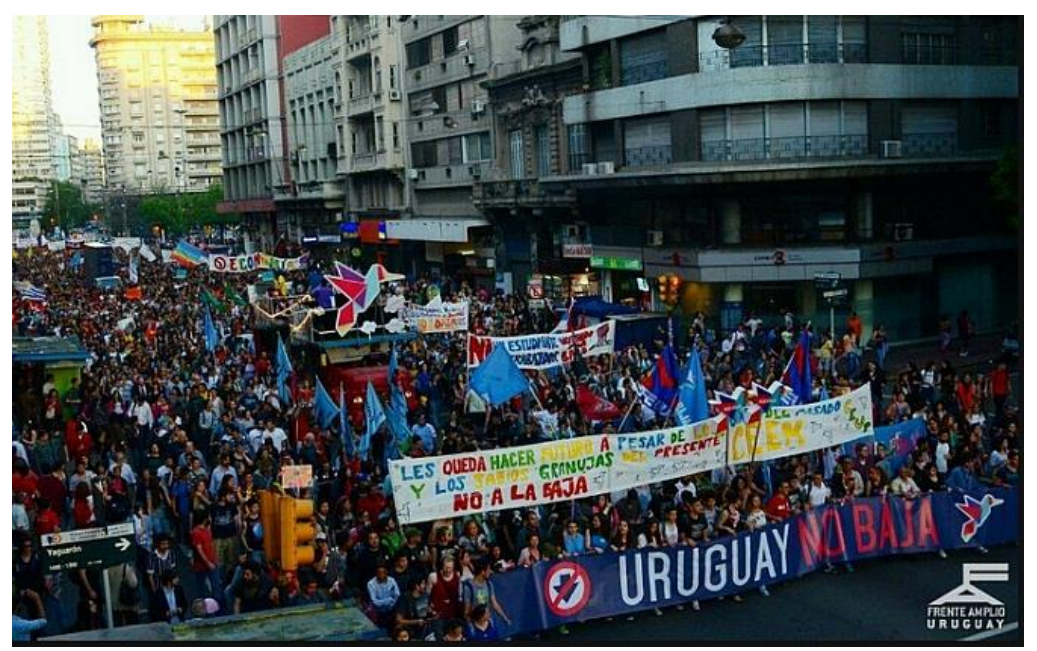

Figura 3: Marcha de cierre de la campaña "No a La Baja” llevada a cabo el 16 de octubre de 2014, a diez días del plebiscito.

En este punto, se considera que los estudios en comunicación de las últimas décadas, tan atraídos epistemológicamente por las complejidades de los procesos culturales y por la necesidad de pensar la cultura en tanto cultura mediática, ha descuidado la mirada sobre los efectos y sobre la cantidad de producciones que están pensando en las audiencias y en los fines en términos de estrategias comunicacionales. La campaña uruguaya "No a la Baja" ha sabido converger los lenguajes y soportes que provee la producción industrial con los procesos de circulación digitales y de medios masivos tradicionales, más las formas de recepción y apropiación. Cabe destacar que la campaña comenzó y terminó con una marcha masiva en Montevideo con ocupación del espacio público, retomando las consignas y los símbolos de los productos comunicacionales. Lo que lograron es un desplazamiento contrario al que describen García Canclini y Martín-Barbero. Mientras que lo masivo logró borronear las particularidades de lo popular para homogeneizar las diferencias en un plano de igualdad simbólica, este movimiento, parado desde los márgenes, desde la representación de una minoría, pudo emplear lo masivo para darle forma a esas particularidades populares, para mostrarlas representadas. En este sentido advierte Canclini sobre los movimientos sociales:

Su acción política y social suele ser de corto alcance (...) porque reinciden en los equívocos del folclorismo y el populismo. Confían en la multiplicación microsocial de sus acciones, sin considerar que las grandes constituyentes de las formas de pensamiento y sensibilidad populares- las industrias culturales, el Estado- sean espacios en los cuales haya que hacer presente los intereses populares o luchar por la hegemonía (2013: 249). 


\section{Participo donde me veo/siento imaginado}

Existe una narrativa, un discurso estético y político que se va instalando con la repetición. Entre los factores que aglutinan esta narrativa se encuentra la idea de una "generación no a la baja", en este sentido se pone en primer lugar de la representación a los y las jóvenes como protagonistas. Se reiteran palabras como "causa" y "juntos" y no intervienen en los discursos argumentos complejos. Se trata de frases cortas, llamativas e impactantes: "Si es otra la escuela, son otras las secuelas". Se prima la producción audiovisual y el uso de estrategias transmedias. Por ejemplo, en el caso del corto "Dieciséis" luego de su presentación formal, el Colectivo Catalejo lo compartió en YouTube y propuso en Facebook una campaña en relación con el título "Crecer con oportunidades", que es una de las frases que más se repite en el documental. La propuesta fue que cada amigo de Facebook comparta una imagen de sí mismo sosteniendo una foto de cuando era chico. Lo significativo es el énfasis en el carácter emocional y en la historicidad de los sujetos. A partir de una imagen se despliegan nociones respecto a las trayectorias y las experiencias diversas al asociarlas con la frase "Crecer con oportunidades".



Figura 4: Imagen propia de las fotos de la página de facebook del Colectivo Catalejo respecto a la campaña "Crecer con oportunidades". 
Esta implicancia de lo emocional es una de las características de los nuevos lenguajes y soportes digitales que convergen perfectamente con la lógica seductora y de encantamiento del entretenimiento: la imposibilidad de ver escindida las cuestiones racionales de las sentimentales. Están ahí, como todo. Están ahí en nuestras pantallas, en nuestra privacidad, nos interpelan en lo más íntimo. Al respecto, indica Martín-Barbero:

\begin{abstract}
La comunicación aparece (...) como lugar de dos estratégicas oportunidades: primera, la que abre la digitalización posibilitando la puesta en un lenguaje común de datos, textos, sonidos, imágenes, videos, desmontando la hegemonía racionalista del dualismo que hasta ahora oponía lo inteligible a lo sensible y lo emocional, la razón a la imaginación, la ciencia al arte, y también la cultura a la técnica y el libro a los medios audiovisuales; segunda: la configuración de un nuevo espacio público y de ciudadanía en y desde las redes de movimientos sociales y de medios comunitarios (2002: 4).
\end{abstract}

En el spot \#TangoNobaja es posible analizar cómo la cuestión emocional se entrelaza con lo popular. Pero ese cruce está espectacularizado. Es contado -atención a la importancia del verbo contar- estéticamente prolijo, hay frases guionadas, planos pensados y estrategias comunicacionales, por ejemplo: se mezclan zapatos de baile de gamuza negra y roja, con zapatillas de lona que parecen ser de niños o niñas. Los personajes que se observan son jóvenes y personas adultas. Hay colibrís colgados en toda la sala y una banda tocando en vivo.

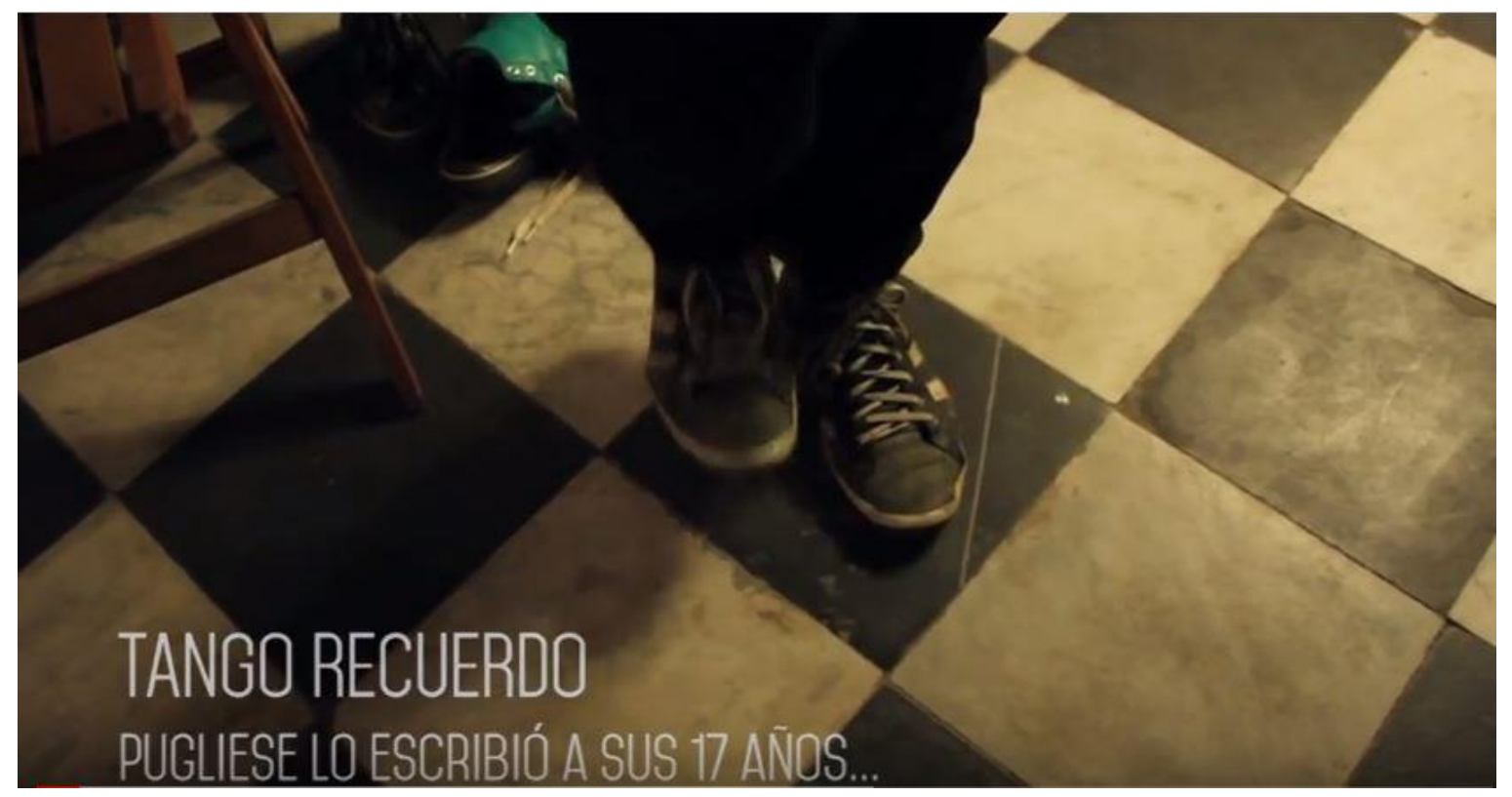

Figura 5: Imagen propia del video “\#TangoNoBaja” publicado en Youtube. 
El típico tango compadrito va sonando a medida que se llena la pista de baile al tiempo que la profesora es enfocada en planos apartados mientras realiza un análisis de lo que implicaría "sacar a un nuevo integrante -que no sabe bailar- de la pista". De manera sintética y emotiva, el razonamiento empieza a relacionarse con los argumentos de no bajar la edad de imputabilidad, aunque nunca se mencionan estas palabras.

\footnotetext{
En el tango y en la telenovela, en el cine masivo y en la nota roja, lo que conmueve a los sectores populares, dice Martín Barbero, es el drama del reconocimiento y la lucha por hacerse reconocer, la necesidad de recurrir a múltiples formas de socialidad primordial (el parentesco, la solidaridad vecinal, la amistad) ante el fracaso de las vías oficiales de institucionalización de lo social, incapaces de asumir la densidad de las culturas populares (García Canclini, 2013: 258).
}

La estructura del spot, que no dura más de cinco minutos apela al tango en tanto símbolo de la cultura popular, asociado con la identidad nacional. Sin embargo, en ningún momento el spot nombra al Estado en relación a la baja, sino que recurre a las dinámicas propias del baile para explicar el problema, estrategia que termina de reforzar la docente con la siguiente frase: "Yo creo que no puede ser como sociedad que la única solución sea sacar del medio, sacar de la pista al que no nos deja bailar en paz y mucho menos pensar que nunca va a aprender a bailar, porque eso es bajar los brazos y nosotros no podemos bajar los brazos en el tango, porque si no, no podemos caminar (...) Nosotros no bajamos los brazos, nosotros abrazamos".

\section{A modo de conclusión}

El imperio de lo visual y/o audiovisual en tanto elementos de instantaneidad signan la construcción de sentido de los enunciados y las grandes narraciones de las organizaciones sociales y políticas. La sociedad del espectáculo no deja afuera a los movimientos sociales que al calor de los ochenta comenzaron a diversificar sus luchas en torno a ciertos derechos humanos.

\footnotetext{
Estamos ante la configuración de un ecosistema comunicativo conformado no sólo por nuevas máquinas o medios, sino por nuevos lenguajes, sensibilidades, saberes y escrituras, por la hegemonía de la experiencia audiovisual sobre la tipográfica, y por la reintegración de la imagen al campo de la producción del conocimiento (Martín-Barbero, 2002: 6).
} 
Para entender hoy esas narrativas estéticas es imprescindible analizar la comunicación desde los procesos de convergencia y las narrativas transmedias. ¿Por qué mirar estos procesos complejos, productos de las globalizaciones? Para evitar caer en la mirada instrumentalista del proceso global, que interconecta lo que vale mientras excluye lo que no necesita, y situar la mirada en la cultura. Sólo desde el relato visibilizado de las experiencias territorialmente situadas, será posible restituirle a los movimientos de minoría un lugar en la lucha hegemónica en el marco de la globalización y de la hipermediatización de la política.

La pretensión de este breve artículo es pensar estas estrategias comunicacionales transmedias como los nuevos manifiestos de los movimientos sociales. Manifiestos que se crean y recrean en el hacer diario. Lo instantáneo, lo volátil y lo contingente del hoy conlleva la creación y funcionamiento permanente de dispositivos flexibles que puedan reacomodarse ante las distintas situaciones políticas. En cada pieza gráfica, sonora y audiovisual de la Campaña hay una parte de ese manifiesto, aunque nos sería imposible encontrar la totalidad en un sólo lugar y aún más difícil encontrarla de forma escrita.

Parafraseando a Siqueiros, se trata de sacar la producción de argumentos en defensa de derechos humanos de los lugares de acuerdo y exponerlos mediante narrativas estrategicas hacia el resto de la sociedad que desconoce o disiente. Existen tambien como transfondo vanguardias y hay manifiestos, pero los recursos para dar el debate público son diferentes.

Uno de los principales méritos de la campaña "No a la Baja" es que pudo articular nociones del campo popular: la lucha por los derechos de los niños y las niñas, ningún pibe nace chorro, nace pobre, muere preso, etcétera pero sin escapar a lo que Martín-Barbero llama la "abrumadora emergencia de una razón comunicacional", sin desconocer y aún más importante, apropiando y resignificando los dispositivos que como fragmentan y dislocan, conectan, comprimen y globalizan. La visibilidad que logró la campaña hizo aliados en todo el continente y en otros países del mundo que conocen el ejemplo uruguayo. En esto reside pensar la identidad hoy, como proceso relacional, móvil y desanclado.

La campaña "No a la Baja" pudo generar estéticas de identificación que nuclearan a los jóvenes y adultos en este gran concepto "generación no a la baja", que no es un concepto vacío, sino que en base a gustos socialmente legitimados y determinados por la lógica del entretenimiento, puso una narrativa estética y un discurso político a disposición de las minorías en la calle.

\section{Notas}

(1) Ver Urdaniz, Anabel (2017). "Derechos de niños y de niñas: los sentidos en tensión entre los marcos legales y los discursos de los medios". Revista Oficios Terrestres. Recuperado de http://sedici.unlp.edu.ar/handle/10915/60365 
(2) En el caso de la Argentina, en 2005 fue promulgada la Ley de Protección Integral de los Derechos de las niñas, niños y adolescentes, en línea con la Convención Internacional sobre los derechos del Niño. Recuperado de http://servicios.infoleg.gob.ar/infolegInternet/anexos/110000-114999/110778/norma.htm

(3) Ver página web de la campaña "No a la Baja" Uruguay: http://noalabaja.uy/

(4) Ver página web del Colectivo Catalejo: http://www.colectivocatalejo.org/crecer

(5) Ver videoclip Nada Crece a las Sombras https://www.youtube.com/watch?v=gV_bubMoUEA

\section{Bibliografía}

Alfaro Siqueiros, D. J. (1933) Manifiesto Muralista. Recuperado de http://www.fba.unlp.edu.ar/muralismo/imagenes/descargables/manifiesto_siqueiros.pdf

Alonso, M. (2016). El sistema de las artes y la primera modernidad en América latina: la construcción de un arte nacional. En Rueda, M. de los Á. Revoluciones, apropiaciones y críticas a la modernidad. La Plata: Facultad de Bellas Artes, UNLP.

Baudelaire, Ch. (1863). El pintor de la vida moderna. Recuperado de http://s3.amazonaws.com/lcp/qwerty/myfiles/baudelaire.pdf

Berman, M. (2014). Todo lo sólido se desvanece en el aire. Experiencia de la Modernidad. Madrid: Siglo XXI.

Butler, J. (2004). Lenguaje, poder e identidad. Recuperado de http://blogs.macba.cat/pei/files/2010/10/Butler-Judith-Lenguaje-poder-e-identidad.pdf

Carrillo, C. V. (enero-julio de 2000). Los manifiestos vanguardistas latinoamericanos, un espacio de reflexión. En Cifra Nueva, 11, pp.19-24Trujillo. Recuperado de http://www.saber.ula.ve/bitstream/123456789/18837/1/articulo2.pdf

Cordova Iturburu C. (2009). Arte, revolución y modernidad. Página/12. Recuperado de https://www.pagina12.com.ar/diario/suplementos/espectaculos/6-12610-2009-0120.html

Escobar, T. (1998). Las otras modernidades. Notas sobre la modernidad artística en el cono Sur: el caso paraguayo. Recuperado de http://www.esteticas.unam.mx/edartedal/PDF/Queretaro/complets/TicioEscobar.PDF

García Canclini, N. (2013). Culturas Híbridas. Estrategias para entrar y salir de la modernidad. Buenos Aires: Ed. Paidós.

Geymonat, A. A. (2011). El Manifiesto Artístico en Latinoamérica. Su Narrativa Textual e Histórica. Revista de Artes y Letras, Universidad Nacional de La Plata.

Largometraje Dieciséis. Recuperado de https://www.youtube.com/watch?v=h4dqtkyYjSk\&t=21s Grupo Espartaco (1961). Manifiesto. Recuperado de http://www.fba.unlp.edu.ar/muralismo/imagenes/descargables/manifiesto_grupo_espart aco.pdf 
Martín-Barbero, J. ( 2002). La globalización en clave cultural: una mirada latinoamericana. En Coloquio Internacional "Globalismo y Pluralismo". Montreal, España. Recuperado de http://www.er.uqam.ca/nobel/gricis/actes/bogues/Barbero.pdf

Martín-Barbero, J. (2003). De las Masas a la masa. En De los medios a las mediaciones. Colombia: Ed. Gustavo Gili.

Rincón, O. (2006). Culturas mediáticas. En Rincón, O. Narrativas mediáticas. O cómo se cuenta la sociedad del entretenimiento. Barcelona: Ed. Gedisa.

Schwartz, J. (2002). Las vanguardias latinoamericanas. FCE, México. Recuperado de https://es.scribd.com/doc/94257906/

Spot "Nada crece a las sombras". Recuperado de https://www.youtube.com/watch?v=gV_bubMoUEA

Spot Tango No Baja. Recuperado de https://www.youtube.com/watch?v=kns9nmVvY54

UNICEF (2016). Las edades mínimas legales y la realización de los derechos de los y las adolescentes. Una revisión de la situación en América Latina y El Caribe. Recuperado de https://www.unicef.org/lac/20160406_UNICEF_Edades_Minima_Esp(1).pdf 